\title{
Editorials
}

\section{Type 3 errors, pill scares, and the epidemiology of oral contraception and health}

As oral contraception (OC) is one of the most widely used medications of our time and used by perfectly fit women for long periods of time its safety has been investigated in thousands of epidemiological studies. Still scientific, epidemiological and whole communities find the information difficult to take in and respond to. It is complicated because contraceptive habits change, OC hormonal compositions change and the epidemiology is therefore forever moving, checking out new uses and new formulations. Recently this area has been greatly enlightened by enormous overviews of much of the more controversial epidemiology-particularly as it relates to breast cancer risk.

The recent overview of the world literature essentially finds a slight increase in risk among current OC users that diminishes with time since stopping OC use until, after 10 years, there appears no excess risk. This is of course very reassuring news for millions of women worldwide who may be vaguely aware that breast cancer is a disease with a hormonal aetiology and hence the pill is thus often held to be suspect, while being a brilliant contraceptive. To what extent do analytical epidemiologists have a part to play in pointing out that such legitimate reassurance, from apparently hard evidence, may be seriously misplaced, when it is impossible to know?

The possibility of a serious type 3 error (that is, believing an explanation that turns out to be wrong, usually because it is difficult to know) in the epidemiology is always real and usually underplayed, because it is never clear when and how it should be discussed. This is because reliable quantification of the probability of a type 3 error is much more complicated than the quantification of type 1 and 2 error probabilities; indeed it is mostly impossible. A type 3 error might occur, for example, where the true nature of a (biological) phenomenon is not easily or totally observable because of unavoidable methodological limitations and where an explanation of facts as they are observed appears (almost) sufficient, when in fact it is not. This is an intrinsic limitation of the parsimonious epidemiological explanation, which should normally be encouraged, of course. Herein lies the central dilemma: good simple explanations are better than complicated ones, unless they turn out to be wrong.

To be the prophet of doom (or of glory) is an uncomfortable position in such uncertain circumstances. This is particularly because one can too easily be associated with the belief, held by some, that notwithstanding the evidence, the pill really does cause a serious increase in breast cancer risk. Where the safety of a product is so massively important beliefs are always strongly held, which makes dispassionate discussion difficult. And in the particular circumstances of OCs of course "pill scares" are a frequently observed and regrettable phenomenon, not to be unnecessarily encouraged or discouraged. We do need however to enable more wisdom somehow; and that is our clear responsibility.
For example, David Skegg ${ }^{1}$ an eminent epidemiologist from New Zealand can always be relied upon to provide a sensible review of the epidemiological evidence about the long term effects on mortality of use of OC. But he, and other expert commentators, tend to ignore the possibility of a delayed effect of long term OC use at a young age on breast cancer. In a recent $B M F$ review of the evidence from the Royal College of General Practitioners Oral Contraceptive Study he does draw attention to some of the intrinsic limitations of the prospective approach in epidemiology. Indeed Doll and Vessey ${ }^{2}$ had warned us about the problems of moving goal posts, alluded to above, in studying the question of contraceptive safety some 20 years earlier. However, Professor Skegg, like most other expert analysts, concludes essentially that pill scares are the product of false alarms and that the pill is safe in the long term despite these methodological limitations. Where, and indeed when, is the place for sensible expression of legitimate anxiety and criticism of whatever undue complacency there might appear be?

This is a case in point:

The RCGP ${ }^{3}$ study recruited its 46000 subjects in 1968 for 14 months. Then the pill was quite new and clearly initiating exemplary studies of the long term effects of OC use was then urgent. However, 1968 was a time in the United Kingdom when obtaining OCs while unmarried was difficult (in most countries impossible) — and consequently the subjects in this study had to be married or living as married. Thus the OC use patterns were unrecognisable by today's standards, where long term use by young, unmarried women is now completely normal. ${ }^{4}$ In the RCGP study such use is very unusual. Then the pill was used largely for family spacing, now it is used largely for preventing unwanted pregnancies among the young.

As far as breast cancer is concerned this rather obvious observation could be crucial in the interpretation of the epidemiology, because we know that breast cancer risk is increased among women for whom the time between menarche and first full term pregnancy is longest. Thus exposure to endogenous female hormones in this period does seem to increase risk, and of course this naturally begs the questions of whether exposure to exogenous female hormones might additionally increase the risk. What can we learn form the existing epidemiology?

Meta analyses of the association of OC use and breast cancer from around 54 studies worldwide suggest, as mentioned above, no long term effect of OCs on breast cancer risk. ${ }^{5}$ But OCs were not commonly used by unmarried, nulliparous women in the UK until the $1970 \mathrm{~s} .{ }^{6} 7$ Moreover, breast cancer is a disease with a long latency between initiation and clinical presentation. ${ }^{8}$ Indeed sometimes there are over 20 years between relevant exposure and any sign of an increased risk, particularly if that exposure is among young women. ${ }^{9}$ Thus to know what the effect of long term early OC use on early stage breast carcinogenesis might be requires good studies to be conducted in the late 1990s. The RCGP study has few women with such use and the 
global overview, as we shall see, probably includes too little long term follow up.

Exogenous hormones are unlikely to be carcinogenic, but they may be co-initators, and induce epithelial changes whereby initiation (random or otherwise) is more likely. ${ }^{10}$ Recent work on the pathology of breast specimens, removed for benign conditions among young women, indicates that standardised epithelial proliferation rates in the resting breast are markedly increased among nulliparous OC users. ${ }^{11}$ If the effect of OCs on endometrial and ovarian cancer is via a reduction in mitotic activity, then what might be the effect of an increase on the resting breast at a young age? The hypothesis that (long term) OC use before first pregnancy ${ }^{12}$ may have a specific, indirect and much delayed effect ${ }^{13}$ is thus particularly germane.

Computer simulations ${ }^{14}$ indicate that delays in the manifestation of such an effect may give rise to systematic bias in estimates of risk until possibly 2010, resulting from attenuated estimates consequent upon insufficient follow up. That is if long term OC use before first pregnancy is associated with a delayed effect from early stage precarcinogenic stimulation, then estimates of ultimate relative risk could, until now, be seriously attenuated. These estimates might also vary considerably before then. Most of the 54 studies combined in the Lancet overview were recruiting cases before the 1990s when estimates of relative risk for OC use before first pregnancy would be expected to be around unity. This is because they would include few subjects with both long term use before first pregnancy and who by then had had long term follow up.

In fact fewer than $1 \%$ of cases and $0.5 \%$ of controls reported using OCs before first pregnancy for five years and for whom there was more than 15 years of subsequent follow up. ${ }^{15}$ There is clearly some power to detect an effect from the 154000 in the overview and the pooled estimated relative risk of subsequent breast cancer is actually a little less than unity. But because also $1 \%$ of the subjects had unknown OC exposure in these data such results cannot be the last word, as OC use before first pregnancy has become so common. Even enormous data sets with less than $1 \%$ relevant exposure are susceptible to considerable bias from control selection, reporting bias and other artefacts. If the latent period is 20 years then there are only 76 exposed cases, which is $0.2 \%$, of the entire world epidemiology accumulated so far; which is hardly representative of OC use patterns in many countries 20 years ago.

Appropriate methods of analysis, taking account of a latent effect, have already found some indication of such effects $^{16}$ but not with any reproducibility, ${ }^{17}$ although another meta analysis (combining 47 studies in 1991) confirms the particular effect of OC use before first pregnancy, ${ }^{18}$ which result may itself be attenuated by a short average follow up. There have been a whole series of studies, including reanalysis of powerful negative studies, ${ }^{19}$ indicating anyway that the overview may oversimplify too.

Reassuring and strong parsimonious epidemiology from the overview and from the RCGP study can too easily be taken as the final answer to an important public health question. For BSE, no evidence of cross species transmission to humans was irresponsibly taken as evidence for the safety of British beef, when it was far too early to know. ${ }^{20}$ In the current case reassuring evidence from a massive overview of the world literature, including 53000 cases, plus a prospective study of 46000 women is taken by Skegg and many others, not without reason, as strong evidence of no serious detrimental long term effect. But no evidence for something is not evidence (strong or otherwise) for its absence.
Concluding no long term detrimental effect may be premature and may also inhibit new studies of an important possible effect. ${ }^{21}$ Long term OC use before first pregnancy is now common, so is breast cancer among women in their late 40 s. Only now can there be enough long term use before first pregnancy sufficiently long ago, to know that it will not be commoner still. Neither the RCGP study nor most of the epidemiology already undertaken can ever answer this question. Breast cancer registration rates could now be reassuring if completely reliable and timely, and if any possible latent period is less than 15 or so years from ending exposure. But if not, we must continue to rely on analytical epidemiology for reliable refutation of this awful possibility.

We all do have to become much better at discussing the uncertainties of the scientific evidence about OC (and other drug and treatment) safety in this country, and elsewhere, and that includes avoiding undue complacency. In 1995, the last pill scare on third generation OCs in the UK apparently was responsible for 30000 excess conceptions, and yet the prompt action of the Committee on Safety of Medicines was reckoned to have saved possibly one life. ${ }^{22}$ Such a response is clearly sub-optimal, and we all have a long way to go before the notion of disease risk can be put in any kind of real and useful perspective. Strong vested interests exist that can easily corrupt perceptions and people live in circumstances where real opportunities for choice are effectively constrained in very different ways. The tobacco debate, for example, corrupts all rational discussion, by its proponents routinely confusing freedom of choice with the addictive use of a lethal product. These risks are horrendous in comparison with current breast cancer risk, ${ }^{23}$ and yet no unwanted pregnancies are ever caused by tobacco scares, whatever they may be.

However, a relative risk of three (say) for breast cancer, with an average latency of 15 years, of say four years of OC use before first pregnancy really cannot be excluded on present evidence. At the moment the chance of a breast cancer diagnosis before age 50 is around 18 per thousand women, or 1 in 50 women in Western cultures. If $50 \%$ of modern women are exposed to this unexludable risk, for them the risk will become 54 per thousand-that is, 1 in 18. Perhaps, because breast cancer under age 50 is meant to be a rare disease, and the argument is neither complicated nor implausible, these matters deserve a wider discussion. Or do they?

KLIM MCPHERSON

Cancer and Public Health Unit, Department of Epidemiology and Population Health, London School of Hygiene and Tropical Medicine, Keppel Street, London WC1E $7 H T$

1 Skegg D. Oral contraception and health. BMF 1999;318:69-70.

2 Doll R, Vessey M. Studying contraception. Br Med Bull 1970;2:973-9.

3 Beral V, Hermon C, Kay C, et al. Mortality associated with oral contraceptive use: 25 years follow up of a cohort of 46,000 women from the Royal tive use: 25 years follow up of a cohort of 46,000 women from the Royal
College of General Practitioners oral contraception study. BMF 1999;318:

96-100

Wood R, Botting B, Dunnell K. Trends in conceptions before and after the 1995 pill scare. Popul Trends 1997;89:5, 12.

5 Breast Cancer and Hormonal Contraceptives. Lancet 1996;347:1713-27. 6 Dunnell K. Family formation. OPCS. London: HMSO, 1976.

7 Bone M. The family planning services: changes and effects. OPCS. London: HMSO, 1978

8 Tokunaga M, Noreman JR, Asano M. Malignant breast tumours among atomic bomb survivors: Hiroshima and Nagasaki. I Natl Canc Inst 1979;62:1347-59.

9 Greenberg ER, Barnes AB, Ressegu IE, et al. Breast cancer in mothers given diethylstilbestrol in pregnancy. $\mathrm{N} \mathrm{Engl} \mathrm{F} \mathrm{Med} \mathrm{1884;311:1393-7.}$

10 Thijssen JH. Oestrogens, progestins and breast proliferation. Zentralbl Gynakol 1997;119 (suppl 2):43-7.

11 Anderson TJ, Battersby S, King R, et al. Oral contraception use influences resting breast proliferaration. Hum Pathol 1989;20:1139-44.

12 Drife JO. Breast cancer, pregnancy and the pill. BMF 1981;283:778.

13 McPherson K, Drife JO. The pill and breast cancer: why the uncertainty? BMF 1986:293:709-10.

14 McPherson K, Coope PA, Vessey MP. Early OC use and breast cancer theoretical effects of latency. Br $\mathcal{F}$ Epidemiol Community Health 1986;40: $1240-1$. 
15 Collaborative group on hormonal factors in breast cancer. Breast cancer and hormonal contraception: further results. Contraception 1996;54 (suppl h):1-106S.

16 McPherson K, Vessey MP, et al. Early OC use and breast cancer: results of another case control study. Br f Cancer 1987;56:653-60.

17 Paul C, Skegg DCG, Spears GFS, et al. The pill and breast cancer: why the uncertainty? BMF 1986;293:1432-3.

18 Delgado-Rodriguez M, Sillero Arenas M, Rodriguez-Contreras R, et al. Oral contraceptive and breast cancer. A meta-analysis. Rev Epidemiol Sante Publique 1991;39:165-81.
19 Peto J. Is the CASH study really negative? Lancet 1989;i:552.

$20 \mathrm{McPherson} \mathrm{K}$. Foolish interpretation of BSE/CJD link. Independent 27 April 1996, 16.

21 McPherson $\mathrm{K}$. Latent effects in the interpretation of any association between oral contraceptives and breast cancer. In: Mansel RE, ed. Benign breast disease. Carnforth, Lancashire: Parthenon, 1994.

$22 \mathrm{McPherson} \mathrm{K}$. Third generation oral contraception and venous thromboembolism. BMF 1996;312:68-9.

23 Bunker J, Houghton J, Baum M. Putting the risk of breast cancer in perspective. BMF 1999;317:1307-9.

\section{$\mathrm{JECH}$ and the world wide web}

Visitors to the world wide web can now access the fournal of Epidemiology and Community Health either through the BMJ Publishing Group's home page (http://www.bmjpg.com) or directly by using its individual URL (http://www.jech.com). There they will find the following:

- Current contents list for the journal

- Contents lists of previous issues

- Members of the editorial board

- Subscribers' information

- Instructions for authors

- Details of reprint services.

\section{Hotlink}

A hot link gives access to:

- BMJ Publishing Group home page

- British Medical Association website

- Online books catalogue

- BMJ Publishing Group books.

\section{Suggestions welcome}

The website is at a preliminary stage and there are plans to develop it into a more sophisticated site. Suggestions from visitors about features they would like to see are welcomed. They can be left via the opening page of the BMJ Publishing Group site or, alternatively, via the journal page, through "about this site". 